\title{
Long-term survival and risk factors for failure of the native hip joint after operatively treated displaced acetabular fractures
}

John Clarke-Jenssen MD ${ }^{1}$, Olav Røise MD, PhD, Professor ${ }^{1,2}$, Stein Arne $\emptyset$ vre MD, PhD ${ }^{3}$, Jan Erik Madsen MD, PhD, Professor ${ }^{1,2}$.

${ }^{1}$ Division of Orthopaedic Surgery, Oslo University Hospital, Norway

${ }^{2}$ Institute of Clinical Medicine, Faculty of Medicine, University of Oslo, Norway

${ }^{3}$ Orthopaedic Department, Innlandet Hospital Trust, Tynset.

Investigation performed at Oslo University Hospital, Department of Orthopaedics 


\section{Abstract}

\section{Aims}

The present study was undertaken to describe the long term survival of the native hip joint after ORIF of a displaced acetabular fracture. We also present long term clinical follow up and risk factors associated with a poor outcome.

\section{Patients and Methods}

253 patients operated from 1993 to 2005 with average age of 42 (13-78) years and a mean follow up of 11 (1-20) years were identified from our pelvic fracture registry. There were 99 elementary and 154 associated fracture types. For the long term clinical follow up, 192 patients with complete data were included. Their mean age was 40 (13-78) years, with an average follow up of 12 (5-20) years.

\section{Results}

Thirty-six patients received a THR. The overall 10-year survival of the native hip joint was $86 \%$ (95\% Cl, 81\%-90\%) and the 20 -year survival was $82 \%$ (95\% Cl, 76\%-87\%). Femoral head injury and acetabular impaction were the strongest predictors for failure, with the long term survival rate falling towards $50 \%$. For patients aged above 60 the survival fell toward $0 \%$ at three years when both these risk factors were present.

\section{Conclusion}

The long term survival of the native hip joint after acetabular fractures was good, but the presence of femoral head injury and acetabular marginal impaction proved to be strong predictors for failure, especially in patients above 60 years. Elderly patients with both these risk factors present may be better treated with a combined fracture fixation and primary hip replacement. 


\section{Introduction}

Fractures of the acetabulum are rare but potentially debilitating injuries, with an incidence of approximately $3 / 100000$ patients per year ${ }^{1}$. Historically, most of these fractures were due to high energy trauma. As the world's population grows older there has been a marked increase in the incidence of displaced low energy acetabular fractures in need of operative intervention ${ }^{2}$.

Open reduction and internal fixation (ORIF) of displaced acetabular fractures has since the ground breaking work of Judet and Letournel ${ }^{3}$ become the gold standard for treating these challenging injuries. The goal of the operative treatment is to restore the articular congruency, thus minimizing the risk for secondary joint degeneration and subsequent poor clinical results ${ }^{4,5}$. Older patients with osteoporotic bone tend to have fracture patterns associated with poor outcome after ORIF $^{2}$ and some authors have therefore advocated a combined procedure with ORIF and total hip replacement (THR) when treating these difficult fractures acutely ${ }^{6,7}$.

With this study, we aimed to describe the long term survival of the native hip joint in operatively treated displaced acetabular fractures, the clinical outcome and to identify any indicators of a poor outcome.

\section{Patients and Methods}

The study was approved by our local institutional review board. The patients were identified in our acetabular fracture database, established by one of the senior authors (O.R.). All patients with acetabular fractures have been prospectively registered in the database since 1993. Registration includes data on injury mechanism, fracture characteristics, classification according to Letournel, and treatment options. All patients were offered regular follow up (FU) for up to 20 years. The follow up data included Harris Hip Score (HHS) and Merle $D^{\prime}$ Aubigné \& Postel (MMA) score as modified by Matta ${ }^{8}$. Radiographs were analysed for the presence of osteoarthritis (OA) according to Letournel ${ }^{9}$ and ectopic bone formation was graded after Brooker ${ }^{10}$. Data on complications and return to work were also recorded.

Patients with operatively treated acetabular fractures in the period from 1993 to 2005 were included to allow for 10 years FU. Generally, our guidelines for operative treatment included the presence of an intraarticular step of more than $2 \mathrm{~mm}$, incongruent hip joint and/ or unstable wall fractures. Stability was generally assessed clinically, as described by Tile and Olson ${ }^{11}$, with the help of axial CT scans. Borderline cases were treated according to the surgeon's discretion. In patients with unreconstructable joints, primary THR was considered. Serious medical comorbidities might contraindicate surgery. Patients with fractures older than 3 weeks $(n=1)$ and patients operated with a primary THR were excluded $(n=4)$, as were patients with ipsilateral femoral head fractures $(n=2)$. We identified 286 patients eligible for inclusion into the present study. For the hip, joint survival analysis 253 patients were included, with an average FU of 10.8 (1.1-20.7) years, excluding those who were lost to FU, 
or deceased within 1-year post operatively (figure 1). In the survival analysis failure was defined as conversion to a THR.

\section{Radiographic evaluation}

Patients were evaluated with three standard radiographs, including Anteroposterior (AP) and Judet views. Computer tomography (CT) scans were performed preoperatively in $96 \%$ of the cases (243 patients). All patients were evaluated with the three standard radiographs postoperatively and at each FU visit. The amount of intraarticular step and diastasis were measured both preoperatively and post operatively. Presence or absence of fracture lines in the upper $10 \mathrm{~mm}$ of the weight bearing dome were recorded. The presence or absence of femoral head injury and acetabular impaction were identified on the CT scans. The three standard radiographs were analysed for the presence of osteoarthritis (OA) during FU, graded according to Letournel. In this grading system grades $0-2$ is considered to present only mild or no clinical symptoms, while grades 3-5 will cause clinically evident arthritic symptoms ${ }^{9}$.

\section{Clinical evaluation}

For the clinical FU patients with complete data on HHS, MMA score or both at a minimum of 5 years were included. Patients who received a THR were excluded (Figure 1). A total of 192 patients (193 hips) with an average FU of 12.2 years $(5.0-20.7)$ were available for analysis of the clinical results.

\section{Surgical procedures}

Mean time from injury to surgery was 5.1 days $(95 \% \mathrm{Cl}$ 4.7-5.5). All fractures were treated by one of four pelvic fracture surgeons, using mainly two standard approaches, namely ilioinguinal or Kocher-Langenbeck (KL). The anterior intrapelvic approach (AIP) with or without a lateral window was only used in $7(3 \%)$ of the cases. $26(10.2 \%)$ of the patients were operated with more extensile or combined approaches. All patients received prophylactic antibiotics, consisting of four doses of $2 \mathrm{~g}$ Cefalotin. The indication for operative treatment and choice of surgical approach generally followed the recommendations of Matta, Letournel and Judet ${ }^{5,12}$, but without an orthopaedic traction table, and patients operated through the KL approach were positioned lateral. Low molecular weight heparin was given to all patients during their hospital stay as prophylaxis against thromboembolic events. Indomethacin was routinely used as prophylaxis against heterotopic ossification for patients operated through a posterior approach until 2003. After that, prophylaxis was used on a case- by case basis.

\section{Statistics}

The survival analysis was made with Stata V14, (StataCorp LP, College Station, Texas, USA). Kaplan-Meier analyses with censoring were performed and differences in survivorship 
between groups were analysed with the Log-Rank test. Hazard ratios were obtained with cox regression. The clinical data were analysed with SPPS v 22 (IBM, Armonk, New York, USA) using Mann-Whitney $U$ test due to the non-normal distribution of HHS and MMA scores. Statistical significance was set to $p \leq 0.05$

\section{Results}

Survival of the native acetabulum

Thirty-six hips were converted to THR during the FU period. The average time to THR was 4.3 (0.6-13.1) years. The overall hip joint survival at 10 years was $86 \%(81-90 \% 95 \% \mathrm{Cl})$ and $82 \%$ $(76-87 \% 95 \% \mathrm{Cl})$ at 20 years (Figure 2). Radiographic evidence of femoral head injury (femoral head fractures excluded) and impaction in the acetabulum were the most significant negative predictors for survival, with long term survival rates dropping to $50 \%$ when both were present (highly statistically significant, $p<0.001$ ) (Figure 3). Interestingly, for patients over 60 years this trend was even more pronounced, although the groups were quite small (Table 1$)$. Survival fell towards $0 \%$ at 3 years $(p<0.001)$ in this age group when both femoral head injury and acetabular impaction were present (Figure 4). Cox regression showed similar results, with a 15-fold increase in the risk for THR when both femoral head injury and acetabular impaction were present in the patient group above 60 years (Table 1 ).

A post-operative intraarticular step over $2 \mathrm{~mm}$ on the AP radiograph was not an independent predictor for failure. However, an equivalent step of more than $2 \mathrm{~mm}$ in the obturator oblique image predicted a decreased hip joint survival ( $p=0.03$ ). And interestingly, all failures in this group occurred during the first 12 months and survival dropped to $63 \%$ after the first year. Cox regression also showed a significantly increased hazard ratio of 3.43 (95\% Cl 1.05-11.21) for a postoperative step in the obturator oblique projection $(p=0.040)$ (Table 2).

Analysing the different fracture types, we found a significantly decreased survival $(p=0.01)$ for associated transverse and posterior wall fractures, with a ten-year survival of $75 \%$ (6084\%). There were no statistically significant differences for other fracture types. We found no statistically significant differences in survival for different age groups (log rank test). However, when applying cox regression with age as the independent variable, there was a slight increase in hazard ratio to $1.03(1.01-1.0595 \% \mathrm{Cl})$ per year age increase for failure of the native hip ( $p=0.01)$. Cox regression showed a 4-6 fold increase in risk for THR if impaction of the femoral head and/ or acetabulum were present. (Table 2)

\section{Clinical results}


The average clinical FU was 12.2 (5.0-20.7) years. Mean HHS was 88 and MMA 16 points. 154 (81\%) patients had a good or excellent HHS score and 147 (77\%) had a good or excellent MMA score (Table 3 ). The presence of femoral head injury significantly reduced the HHS to 83 in the medium to long term FU $(p=0,021)$.

Compared to the average scores, patients with an anterior column fracture had a significantly better clinical score both for HHS with a score of 94, and MMA with a score of 17 , while anterior wall fractures had a significantly worse MMA score of 14 . There were no statistically significant differences in clinical scores for other fracture types (Table 4). We could not find differences in clinical scores for different age groups (40, 50 or 60 years). Neither were there any differences for patients with or without a residual fracture step over $2 \mathrm{~mm}$.

\section{Radiological results}

The average preoperative intraartricular step off were $7.6(0-40) \mathrm{mm}$ (as measured on the three standard radiographs). Post-operative radiographs showed that $218(86 \%)$ fractures were anatomically reduced, 17 fractures $(7 \%)$ were reduced with a maximum of $2 \mathrm{~mm}$ residual displacement and the remaining 18 fractures (7\%) had an average residual displacement of $3.8(3-8) \mathrm{mm}$.

201 patients had a mean radiological FU of 12.1 (5-21) years. 91 (45\%) of the patients showed no signs of OA after a mean FU of 11.4 (5-20) years. Grade 1 OA was present in 47 (23\%) with a mean FU of $12.8(7-20)$ years. 24 (12\%) of the patients had grade 2 OA at a mean FU of 13.1 (9-21) years. 39 (20\%) had grade 3-5 OA after a mean FU of 12.6 (5-20) years. The radiographic results correlated well with the clinical results with 19 points drop in HHS and a 3 points drop in MMA for patients with OA grade 3-5, $p<0.001$ (Figure 5).

\section{Heterotopic ossification}

Heterotopic ossification was graded according to Brooker ${ }^{10}$ and was observed in 53 (26.4\%) of the cases. Grade 1 was most common with 27 cases, 19 patients had grade 2, 6 had grade 3 and 1 grade 4 . There was a significant association between the use of a Kocher-Langenbeck approach and the presence of heterotopic ossification $(p<0.001)$.

\section{Complications}

Complications were seen in 46 (18.2\%) patients, some had more than one. The most common complication were iatrogenic nerve injuries, observed in 17 (6.7\%) of the patients. The nerve injuries included injury to the lateral femoral cutaneous nerve (10 patients), sciatic nerve ( 5 patients), femoral nerve ( 1 patient) and the obturator nerve ( 1 patient). Injuries ranged from temporary loss of sensation to total loss of function. Intraarticular screw placement necessitating hardware removal occurred in 16 (6.3\%) patients, 12 of the cases (75\%) occurred during the first two years. Deep infection requiring surgical 
debridement was seen in 13 (5.1\%) patients and 6 patients experienced a thromboembolic event. The presence of complications did not decrease survival of the native hip, nor worsen the clinical outcome. There were no patient deaths during the first year post operatively.

\section{Discussion}

The main aim of this cohort study was to describe the long-term FU of operatively treated acetabular fractures. The overall hip joint survival was excellent, with $86 \%$ at ten years. The most powerful predictor for failure was femoral head injury and acetabular impaction, especially in patients over 60 years where all hips with both risk factors present were converted to a THR within three years. For patients with surviving hip joints a good clinical function can be expected, and the presence of secondary OA correlated well with clinical scores.

There are few studies reporting on the long term survival of the native acetabulum after acetabular fracture surgery. Tannast et al. reported 10 year survival of $85 \%, 15$ year survival of $81 \%$ and a $79 \% 20$ years survival in their study with 810 patients and an average FU of 10 (2-29) years. ${ }^{13}$. This correlates well with our findings showing $86 \% 10$ year survival and $82 \%$ 15 years survival, our data does not support the calculation of 20 years survival. Mears and colleagues published 424 acetabular fractures with an average of 9 (3-21) years FU and found a survival of the native hip of $88 \%,{ }^{14}$, while Briffa et al. described $84.5 \%$ survival after $11(10-18)$ years FU in 161 patients. ${ }^{15}$

Radiological evidence of impaction in the acetabulum or the femoral head has previously been launched as a negative factor for survival of the native acetabulum ${ }^{13}$. In the present study, they proved to be highly powerful predictors; when both were present the survival of the native acetabulum fell towards $50 \%$ at 10 years. For patients, older than 60 years these findings were even more pronounced, as joint survival fell towards 0 after just 3 years for patients with both femoral head injury and acetabular impaction. Although the number of patients are small and these findings must be interpreted with some caution, they are highly statistical significant, and may indicate that the elderly acetabular fracture patients with marginal impaction and femoral head injury should be considered for acute treatment with a combined hip procedure with ORIF and THR. ${ }^{6,16}$. This is now our preferred treatment option for this specific patient group.

Clinical outcome after operatively treated acetabular fractures is, in most publications, reported using the MMA. Unfortunately, this score is hampered with a pronounced ceiling effect, and its usefulness in acetabular fracture surgery has been debated ${ }^{17,18}$. Even so, we have used this score since the introduction of our database in 1994 and still find it useful in order to compare our results to others. In our cohort, we observed 147 (77\%) patients with good or excellent MMA score and 154 (81\%) patients with good or excellent HHS at average 
of 12 (5-20) years FU and this compare well with the long term clinical results published by others $^{4,5,14,19,20}$.

Accuracy of reduction has been shown to be an important predictor of clinical outcome ${ }^{5,21,22}$. We could not verify this by finding a statistically significant relationship between accuracy of reduction and clinical outcome. However, this may have been due to the relatively low number of patients (8) with a residual displacement over $3 \mathrm{~mm}$. Presence of femoral head injury, however, was associated with a 5-point reduction in HHS, being statistically significant. In previous literature, anterior wall and posterior column involvement have also been described as negative predictors for the result ${ }^{5,14,19}$. In our series, the anterior column fractures did significantly better compared to other fracture types, while the anterior wall fractures did significantly worse. Due to the complexity of Letournels classification and the relatively few fractures in each group these findings must be interpreted with some caution. $A$ relatively high number of our patients developed radiologic signs of $O A$ according to the Letournel grading system, 110 (55\%) patients showed radiographic evidence of any OA, 39 (19\%) had grade 3-5. Patients with OA Letournel grade 3-5 had significantly lower HHS and MMA score when compared to those with grade $0-2$, confirming that Letournels grading system correlates to the clinical long term results.

The reason for why a residual step $>2 \mathrm{~mm}$ in the obturator oblique projection is a significant radiological predictor, might be explained by biomechanics. Olson showed in their experimental study that a malreduced acetabular fracture trough the posterior wall increased the contact and maximum pressure in the weight bearing part of the dome ${ }^{23}$. Konrath and colleagues have also showed that this was the case for fractures trough the anterior column ${ }^{24}$, whereas this is not the case for fractures of the anterior wall, or transverse fractures ${ }^{25,26}$. Thus, malunited fractures through the posterior wall and anterior column might increase the risk of joint degeneration and an inferior outcome, fracture displacement of the anterior column and posterior wall is best visualized on the obturator oblique projection.

The most common complication to surgery was iatrogenic nerve injury in 17 (6.7\%) of the patients, with the lateral femoral cutaneous nerve most frequently damaged. In Mears' series an incidence of iatrogenic sciatic nerve injury of $6 \%{ }^{14}$ was reported, and other authors have reported nerve injuries to occur in 3.5 to $8 \%{ }^{5,19}$. In our series, intraarticular screw placement necessitating reoperation occurred in 16 (6.3\%) patients, notably $75 \%$ of the cases were from the first 2 years of the series and might be attributable to the learning curve - in Mears' series they noted a $3.1 \%$ occurrence of intraarticular screws ${ }^{14}$. Our rate of deep infections necessitating surgical debridement was $5.1 \%$ (13 patients) and is comparable to other authors generally reporting infection rates between $3.5 \%$ and $6 \% 5,14,15,19,27,28$

The present study is a long term follow-up of a quite large cohort and may provide useful insight in this complex patient group, both for survival of the native hip joint as well as clinical outcome. The study presents a cohort of patients with a consistent and well attended 
(88\%) FU. Furthermore, the patients were treated following uniform guidelines by four surgeons at a single centre.

However, the study also has some inherent weaknesses. It represents a long term follow up of a register based cohort, and although prospectively registered, the series is not complete as 34 patients (12\%) were lost to FU. Furthermore, the cohort included all patients operatively treated after a wide variety of injury mechanisms, from low energy falls to severe polytrauma, as well as a spectrum of age from 13 to 78 years. Also, the clinical evaluation of our patients was performed utilizing the HHS and MMA, both criticized for their significant ceiling effects ${ }^{29,30}$. These outcome measures were, however, chosen at the initiation of our registry in 1993 and have been continued because of their widespread use in the reporting of outcome in acetabular fracture surgery ${ }^{5,14,15,22,27}$. With the introduction of more recent scoring systems, we now also include patient reported outcome measures (PROMs) in our FU of operatively treated acetabular fractures

The overall hip joint survival and clinical outcome for patients with operatively treated acetabular fractures are good. Some groups, however, such as patient age 60 and above with both joint impaction and femoral head injury have a high risk of developing debilitating post traumatic arthritis and may possibly be best treated with a combined procedure of ORIF and primary arthroplasty.

\section{References}

1. Laird A, Keating JF. Acetabular fractures: a 16-year prospective epidemiological study. J. Bone Joint Surg. $\mathrm{Br}$ 2005;87-7:969-73.

2. Ferguson TA, Patel R, Bhandari M, Matta JM. Fractures of the acetabulum in patients aged 60 years and older: an epidemiological and radiological study. J Bone Joint Surg Br 2010;92-2:250-7.

3. Judet $R$, Judet J, Letournel $E$. Fractures of the acetabulum: Classification and surgical approaches for open reduction. Preliminary report. J. Bone Joint Surg. Am 1964;46:1615-46.

4. Letournel E, Judet R. Clinical and radiological results of operation within three weeks of injury. In: Elson RA, ed. Fractures of the Acetabulum, 2 ed. Berlin: Springer-Verlag, 1993:565-81.

5. Matta JM. Fractures of the acetabulum: accuracy of reduction and clinical results in patients managed operatively within three weeks after the injury. J. Bone Joint Surg. Am 1996;78-11:1632-45.

6. Herscovici D, Jr., Lindvall E, Bolhofner B, Scaduto JM. The combined hip procedure: open reduction internal fixation combined with total hip arthroplasty for the management of acetabular fractures in the elderly. J Orthop Trauma 2010;24-5:291-6.

7. Boraiah S, Ragsdale M, Achor T, Zelicof S, Asprinio DE. Open reduction internal fixation and primary total hip arthroplasty of selected acetabular fractures. J Orthop Trauma 2009;23-4:243-8.

8. Matta JM, Anderson LM, Epstein HC, Hendricks P. Fractures of the acetabulum. A retrospective analysis. Clin Orthop Relat Res 1986-205:230-40.

9. Letournel E. Late complications of operative treatment within three weeks of injury. In: R.A. E, ed. Fractures of the Acetabulum, 2 ed. Berlin Heidelberg: Springer-Verlag, 1993:541-63.

10. Brooker AF, Bowerman JW, Robinson RA, Riley LH, Jr. Ectopic ossification following total hip replacement. Incidence and a method of classification. J Bone Joint Surg Am 1973;55-8:1629-32. 
11. Tile M, Olson SA. Decision Making: Nonoperative and Operative Indications for Acetabular Fractures. In: Tile M, ed. Fractures of the Pelvis and Acetabulum, 2 ed. Baltimore: Williams \& Wilkins, 1995.

12. Letournel E, Judet R. Anatomy of the Acetabulum. In: R.A. E, ed. Fractures of the Acetabulum, 2 ed. Heidelberg: Springer-Verlag, 1993:17-22.

13. Tannast M, Najibi S, Matta JM. Two to twenty-year survivorship of the hip in 810 patients with operatively treated acetabular fractures. J. Bone Joint Surg. Am 2012;94-17:1559-67.

14. Mears DC, Velyvis JH, Chang CP. Displaced acetabular fractures managed operatively: indicators of outcome. Clin. Orthop. Relat Res 2003-407:173-86.

15. Briffa N, Pearce R, Hill AM, Bircher M. Outcomes of acetabular fracture fixation with ten years' follow-up. J Bone Joint Surg Br 2011;93-2:229-36.

16. Boraiah S, Ragsdale M, Achor T, Zelicof S, Asprinio DE. Open reduction internal fixation and primary total hip arthroplasty of selected acetabular fractures. J. Orthop. Trauma 2009;23-4:243-8.

17. Rice J, Kaliszer M, Dolan M, Cox M, Khan H, McElwain JP. Comparison between clinical and radiologic outcome measures after reconstruction of acetabular fractures. J Orthop Trauma 2002;162:82-6.

18. Ovre S, Sandvik L, Madsen JE, Roise O. Comparison of distribution, agreement and correlation between the original and modified Merle d'Aubigne-Postel Score and the Harris Hip Score after acetabular fracture treatment: moderate agreement, high ceiling effect and excellent correlation in 450 patients. Acta Orthop 2005;76-6:796-802.

19. Giannoudis PV, Grotz MR, Papakostidis C, Dinopoulos H. Operative treatment of displaced fractures of the acetabulum. A meta-analysis. J. Bone Joint Surg. Br 2005;87-1:2-9.

20. Murphy D, Kaliszer M, Rice J, McElwain JP. Outcome after acetabular fracture. Prognostic factors and their inter-relationships. Injury 2003;34-7:512-7.

21. Bhandari M, Matta J, Ferguson T, Matthys G. Predictors of clinical and radiological outcome in patients with fractures of the acetabulum and concomitant posterior dislocation of the hip. J. Bone Joint Surg. Br 2006;88-12:1618-24.

22. Meena UK, Tripathy SK, Sen RK, Aggarwal S, Behera P. Predictors of postoperative outcome for acetabular fractures. Orthop Traumatol Surg Res 2013;99-8:929-35.

23. Olson SA, Bay BK, Chapman MW, Sharkey NA. Biomechanical consequences of fracture and repair of the posterior wall of the acetabulum. J. Bone Joint Surg. Am 1995;77-8:1184-92.

24. Konrath GA, Hamel AJ, Sharkey NA, Bay BK, Olson SA. Biomechanical consequences of anterior column fracture of the acetabulum. J. Orthop. Trauma 1998;12-8:547-52.

25. Hak DJ, Hamel AJ, Bay BK, Sharkey NA, Olson SA. Consequences of transverse acetabular fracture malreduction on load transmission across the hip joint. J. Orthop. Trauma 1998;12-2:90-100. 26. Konrath GA, Hamel AJ, Sharkey NA, Bay B, Olson SA. Biomechanical evaluation of a low anterior wall fracture: correlation with the CT subchondral arc. J. Orthop. Trauma 1998;12-3:152-8.

27. Letournel E. Acetabulum fractures: classification and management. Clin. Orthop. Relat Res 1980151:81-106.

28. Deo SD, Tavares SP, Pandey RK, El-Saied G, Willett KM, Worlock PH. Operative management of acetabular fractures in Oxford. Injury 2001;32-7:581-6.

29. Moed BR, Yu PH, Gruson KI. Functional outcomes of acetabular fractures. J. Bone Joint Surg. Am 2003;85-A-10:1879-83.

30. Ovre S, Sandvik L, Madsen JE, Roise O. Modification of the Harris Hip Score in acetabular fracture treatment. Injury 2007;38-3:344-9. 


\begin{tabular}{|l|c|c|c|c|c|c|}
\hline & \multicolumn{3}{|c|}{ Over 60 years (n=40) } & \multicolumn{3}{c|}{ Under 60 years ( $=213)$} \\
\hline Variable & $n$ & HR (95\%CI) & $p$-Value & $n$ & HR (95\%CI) & $p$-Value \\
\hline Acetabular impaction (AI) & 9 & $4.57(1.09-19.18)$ & $P=0.038$ & 15 & $3.53(1.63-7.66)$ & $p=0.001$ \\
\hline Femoral head injury (FHI) & 5 & $8.36(1.96-35.68)$ & $p=0.004$ & 32 & $4.45(2.10-9.41)$ & $p<0.001$ \\
\hline Al+FHI & 3 & $15.65(3.10-79.10)$ & $P=0.001$ & 19 & $4.72(2.00-11.12)$ & $p<0.001$ \\
\hline Age (increase pr year) & 40 & $1.17(1.03-1.33)$ & $P=0.015$ & 213 & $1.02(0.99-1.06)$ & $p=0.106$ \\
\hline $\begin{array}{l}\text { Residual step >2mm obturator } \\
\text { projection }\end{array}$ & 2 & $2.88(0.35-23.50)$ & $P=0.323$ & 6 & $3.58(0.84-15.22)$ & $p=0.084$ \\
\hline
\end{tabular}

Table 1: Unadjusted hazard ratios obtained by cox regression for different parameters for patients above or below 60 years 


\begin{tabular}{|l|l|l|}
\hline \multicolumn{1}{|c|}{ Variable } & \multicolumn{1}{|c|}{ Hazard Ratio (95\%Cl) } & \multicolumn{1}{|c|}{-Value } \\
\hline Acetabular impaction & $3.97(2.04-7.72)$ & $\mathrm{p}<0.001$ \\
\hline Femoral head injury & $4.99(2.57-9.69)$ & $\mathrm{p}<0.001$ \\
\hline $\begin{array}{l}\text { Acetabular impaction }+ \\
\text { Femoral head injury }\end{array}$ & $5.89(2.83-12.25)$ & $\mathrm{p}<0.001$ \\
\hline $\begin{array}{l}\text { Age (increase per year) } \\
\text { Step }>2 \text { mm obturator } \\
\text { oblique radiograph }\end{array}$ & $1.03(1.01-1.05)$ & $\mathrm{p}<0.010$ \\
\hline $\begin{array}{l}\text { Step }>2 \text { mm iliac oblique } \\
\text { radiograph }\end{array}$ & $0.64(0.09-4.64)$ & $\mathrm{p}<0,040$ \\
\hline \begin{tabular}{l} 
Step $>2 m m$ AP radiograph \\
\hline
\end{tabular} & $2.06(0.49-8.65)$ & $\mathrm{p}<0.655$ \\
\hline
\end{tabular}

Table 2: Hazard ratios obtained by cox regression for different parameters influencing hip joint survival 


\begin{tabular}{|l|c|c|}
\hline \multicolumn{3}{|c|}{ Clinical outcome } \\
\hline Grade & HHS & MMA \\
\hline Excellent & $121(63.7 \%)$ & $43(22.5 \%)$ \\
\hline Good & $33(17.4 \%)$ & $104(53.9 \%)$ \\
\hline Fair & $17(8.9 \%)$ & $24(12.6 \%)$ \\
\hline Poor & $19(10.0 \%)$ & $20(10.5 \%)$ \\
\hline
\end{tabular}

Table 3: Number of patients with graded clinical outcome, according to Harris Hip Score (HHS) and Merlé D'Aubigné \& Postel score (MMA). Percentages in parentheses. 


\begin{tabular}{|l|c|c|l|c|l|}
\hline \multicolumn{1}{|c|}{ Fracture type } & N & Mean HHS & p-Value & Mean MMA & p-Value \\
\hline Posterior wall & 31 & $85(80.5-89.6)$ & 0.105 & $15(14.7-16.2)$ & 0.438 \\
\hline Posterior column & 1 & $100(100-100)$ & 0.241 & $17(17-17)$ & 0.656 \\
\hline Anterior wall & 6 & $78(51.0-95.3)$ & 0.208 & $\mathbf{1 4}(\mathbf{1 1 . 2 - 1 5 . 8 )}$ & $\mathbf{0 . 0 4 9}$ \\
\hline Anterior column & $\mathbf{2 8}$ & $\mathbf{9 4}(\mathbf{9 0 . 6}-\mathbf{9 6 . 3 )}$ & $\mathbf{0 . 0 4 8}$ & $\mathbf{1 7}(\mathbf{1 6 . 0 - 1 7 . 0 )}$ & $\mathbf{0 . 0 2 6}$ \\
\hline Transverse & 12 & $89(76.3-97.7)$ & 0.286 & $16(14.2-17.4)$ & 0.303 \\
\hline Posterior column+wall & 9 & $92(87.3-95.6)$ & 0.983 & $16(14.6-16.8)$ & 0.851 \\
\hline Transverse+ Posterior wall & 36 & $86(81.1-91.1)$ & 0.237 & $15(14.5-16.0)$ & 0.175 \\
\hline T-fracture & 18 & $90(82.3-95.3)$ & 0.562 & $16(14.4-16.6)$ & 0.930 \\
\hline Anterior column+PHT* & 19 & $86(78.0-93.6)$ & 0.597 & $15(14.3-16.5)$ & 0.794 \\
\hline Both column & 33 & $89(83.2-93.6)$ & 0.596 & $16(14.7-16.6)$ & 0.677 \\
\hline
\end{tabular}

Table 4: Mean values for Harris hip score (HSS) and modified Merle d'Aubigné (MMA) score for the different fracture types, tested for significant differences with Mann-Whitney $U$ test. $95 \% \mathrm{Cl}$ in parentheses. Significant values in bold. *Posterior hemi transverse 


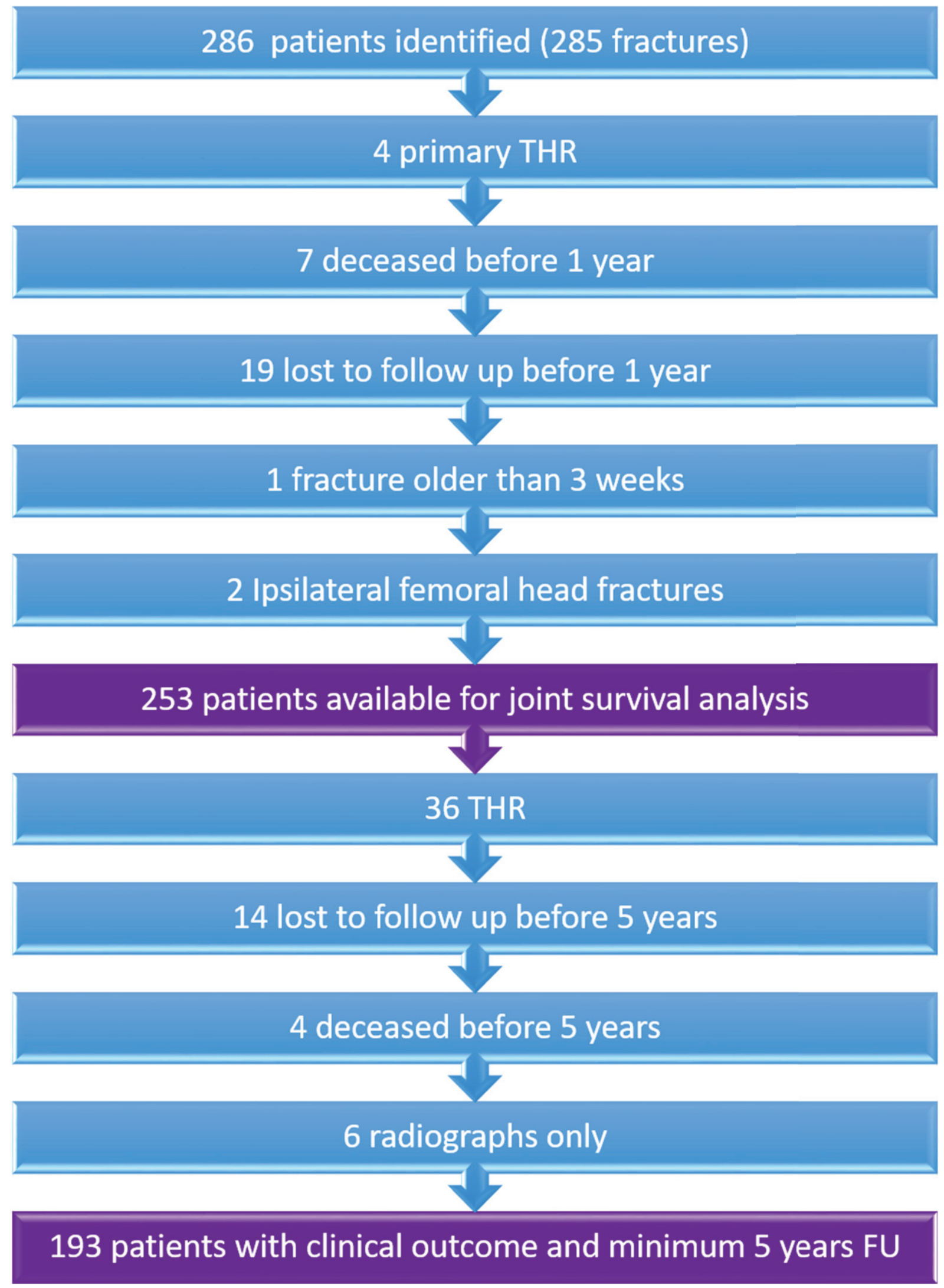

Figure 1: Flow chart describing inclusion of patients. 


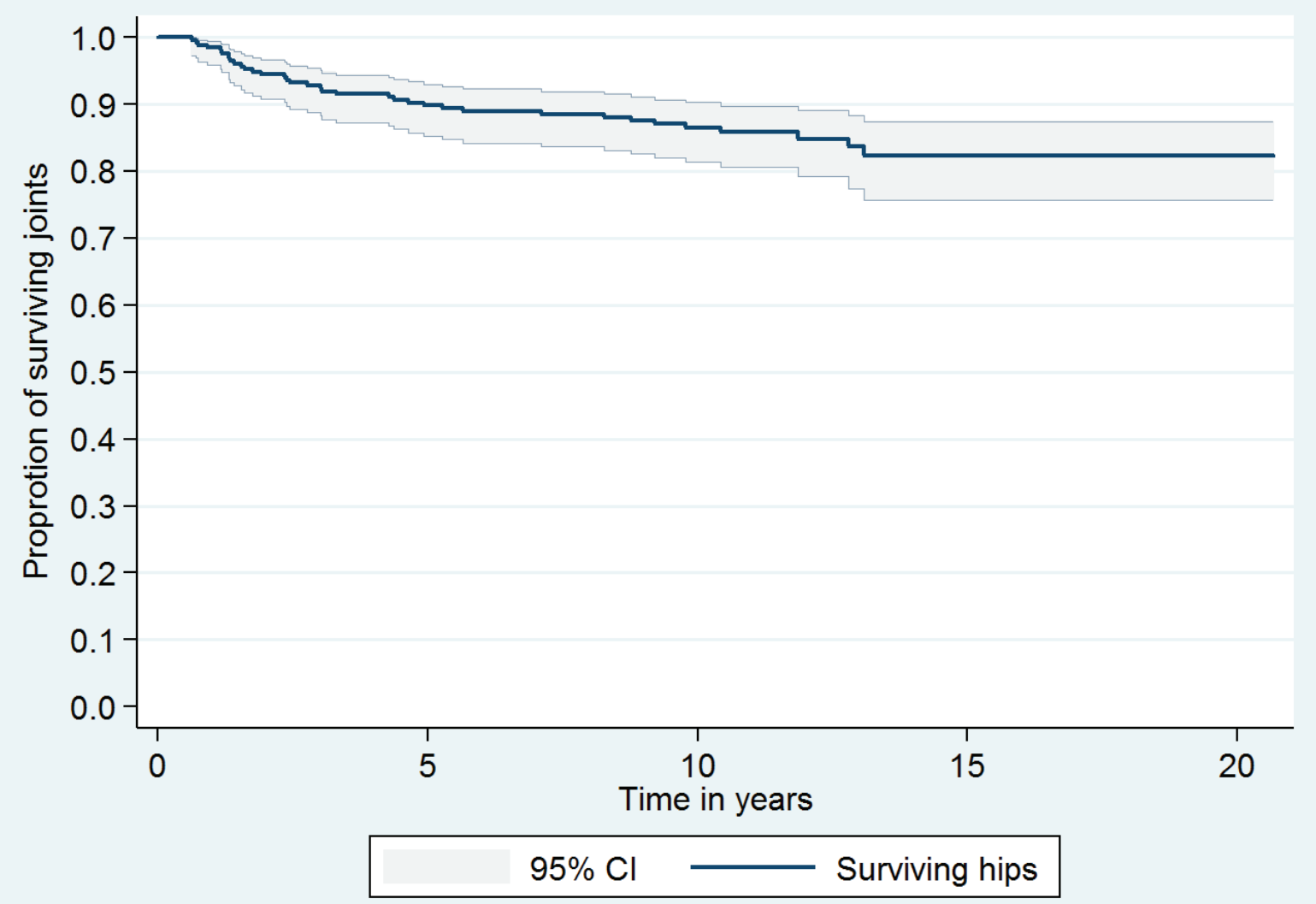

Figure 2: Kaplan-Meier survival curve of the native hip joint in all operatively treated acetabular fractures. 


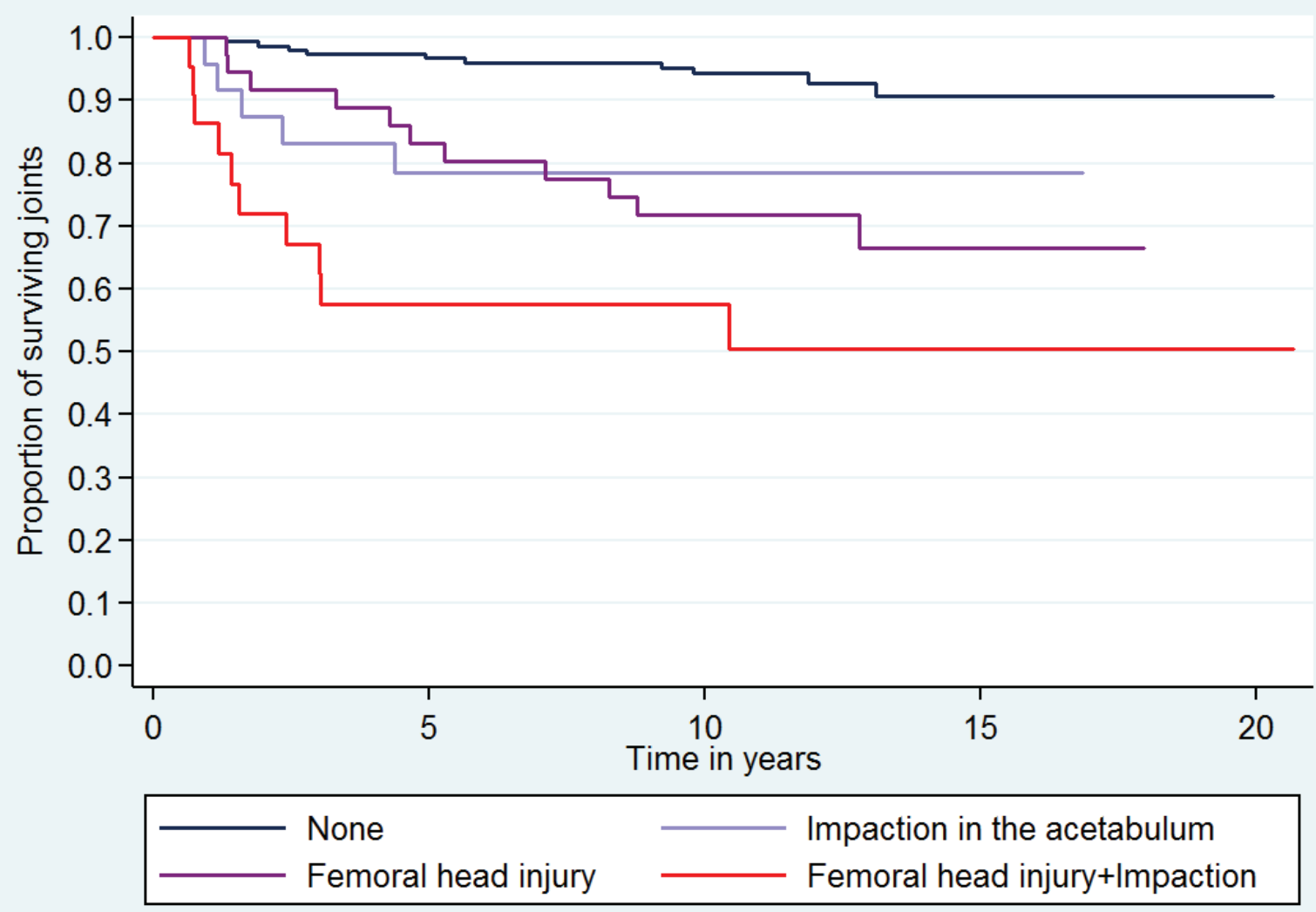

Figure 3: Kaplan-Meier survival estimate as influenced by femoral head cartilage injury and acetabular impaction. 


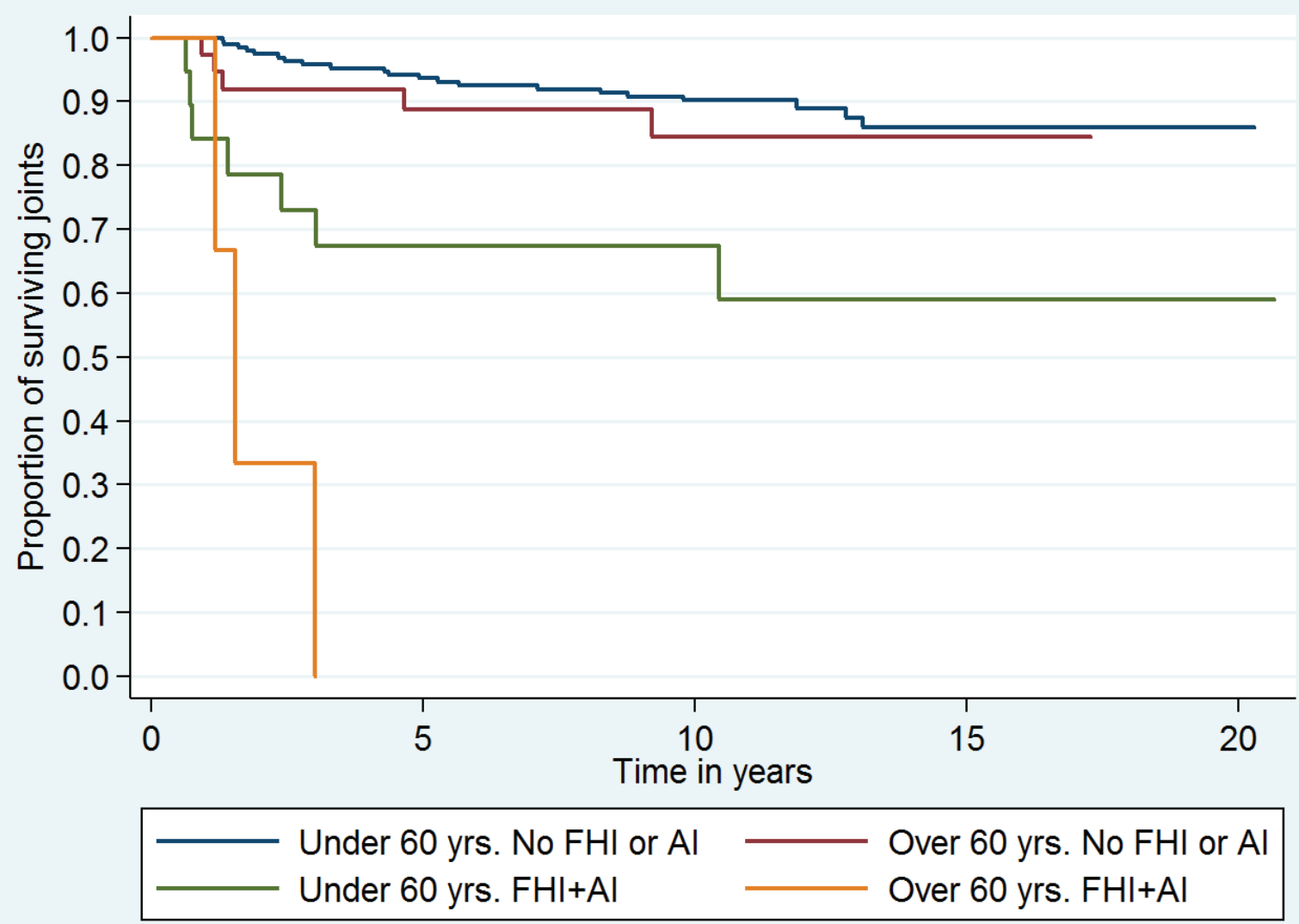

Figure 4: Kaplan-Meier survival estimate as influenced by femoral head cartilage injury (FHI) and acetabular impaction (AI) according to age over or under 60 years. 


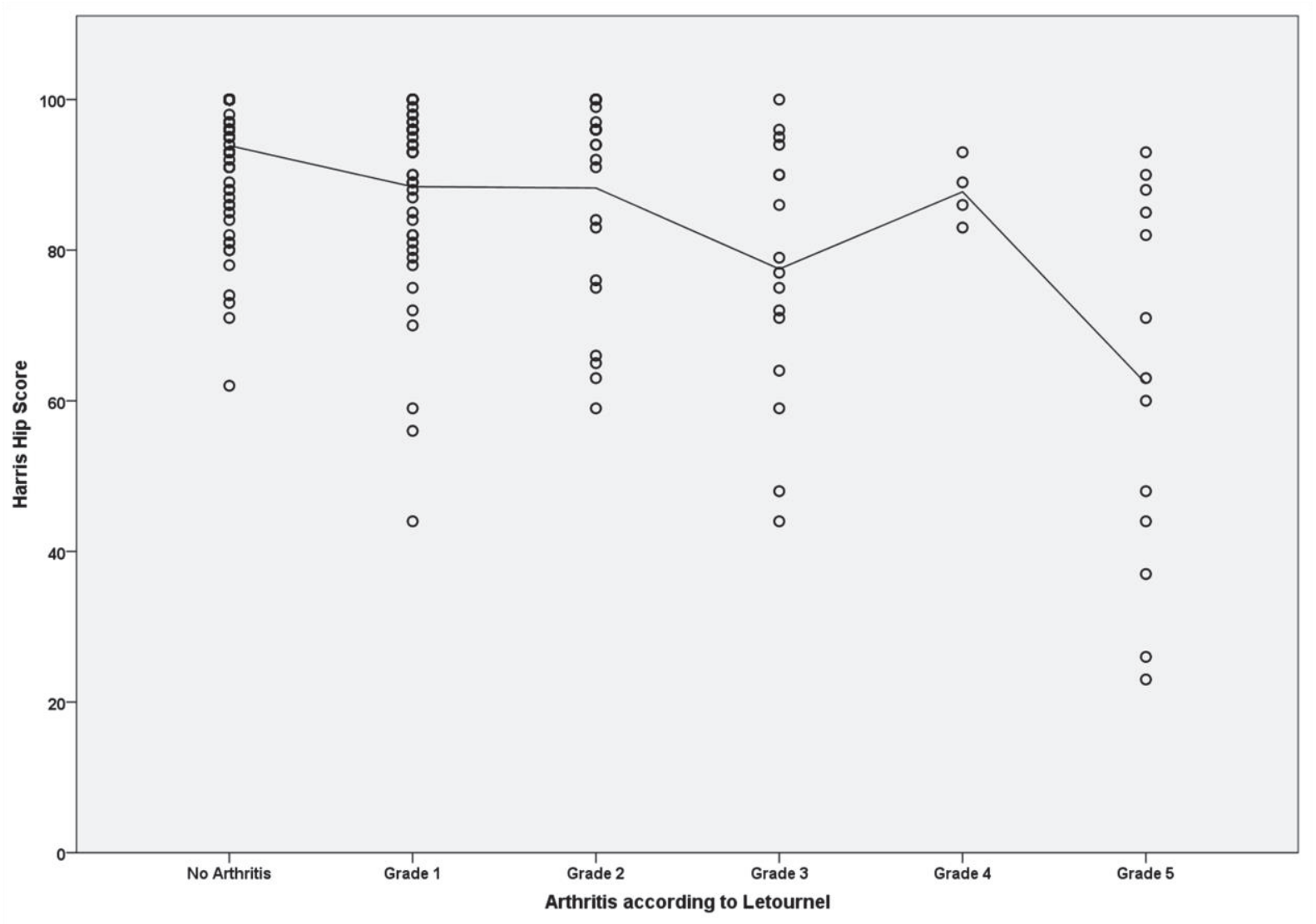

Figure 5A: Scatterplot of Harris hip score against degree of arthritis with interpolation line. 


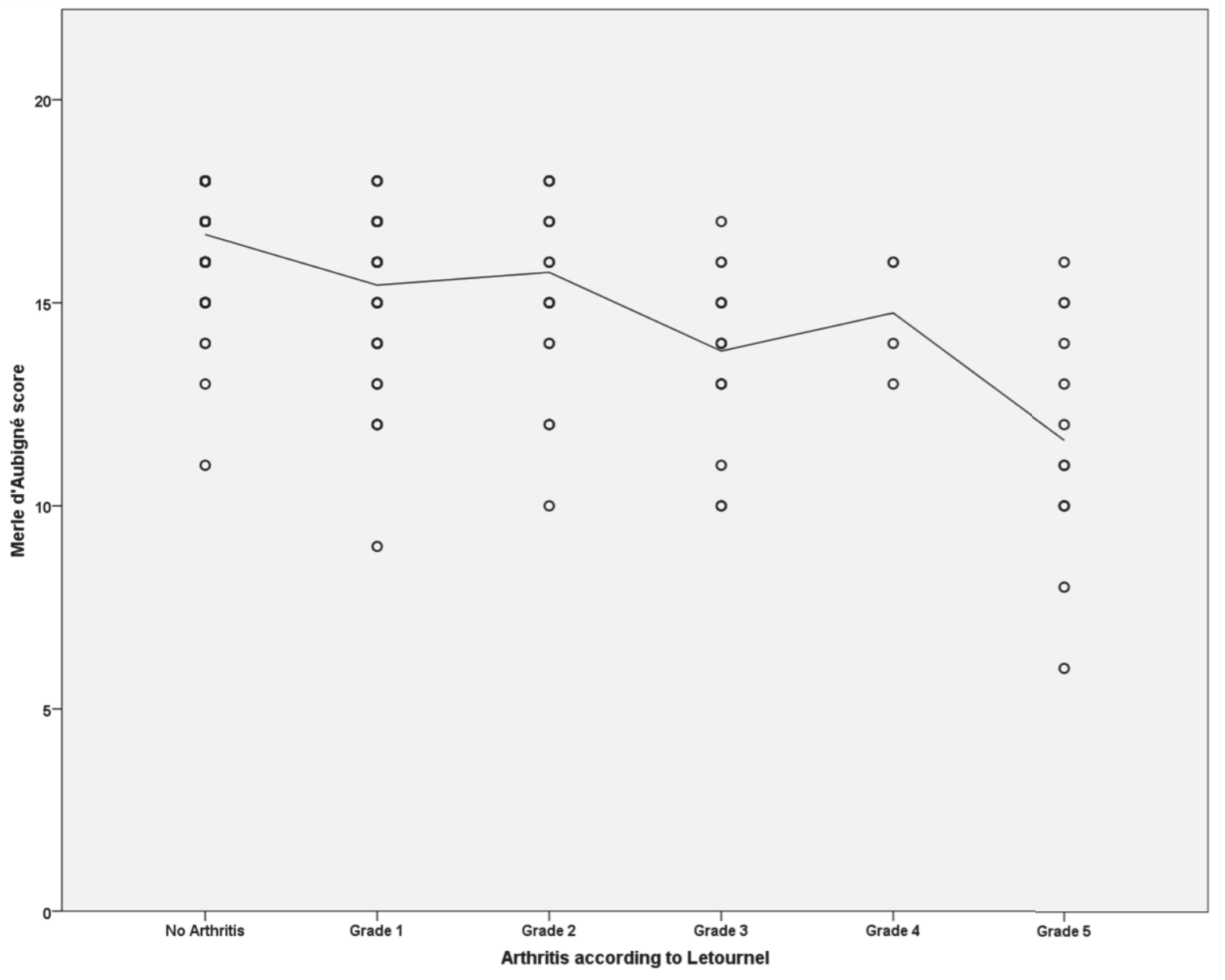

Figure 5B: Scatterplot of Merle d'Aubigné score against degree of arthritis with interpolation line. 